Revista Tecné, Episteme y Didaxis: TED. Año 2014, Número Extraordinario. ISSN Impreso: 0121-3814, ISSN web: 2323-0126

Memorias, Sexto Congreso Internacional sobre Formación de Profesores de Ciencias. 08 al 10 de octubre de 2014, Bogotá

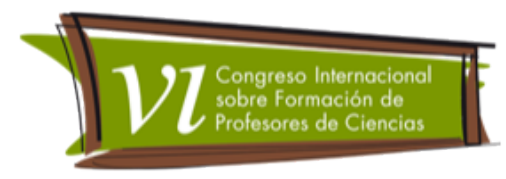

\title{
Sexualidade E Formação De Professores Sexuality And Teacher Formation
}

Laganá, Hylio Fernandes'; Penhalver, Nicole3; Rodrigues, Viviani²

\section{Resumo}

Este trabalho investiga experiências formativas de professoras, num processo pautado pela horizontalidade e não-diretividade, estruturado em grupos de encontro, cujo mote foi a sexualidade na escola básica. O referencial humanista de Carl Rogers fundamenta a prática. A formação analisada envolve 5 licenciandas, atuantes numa escola estadual em parceria com uma universidade federal, na cidade de Sorocaba/SP/Brasil. Partindo de um problema reincidente verificado na escola sobre gravidez de alunas, formou-se um grupo de encontro para debater modos de abordar essa temática nas aulas de ciencias. Evidenciase a importância da liberdade para agir, da experiencia e da reflexão sobre a ação como componentes centrais da formação docente, assim como a necessidade de ampliar a percepção para além dos conteúdos anatomicos e fisiológicos inerentes às ciencias biológicas.

\section{Palavras-Chave}

Formação docente, sexualidade, autonomia

\section{Sexualidade e escola}

A sexualidade é uma temática importante para ser tratada com adolescentes na educação básica, seja por estar preconizada nos Parametros Curriculares Nacionais (PCN Brasil, 1997), seja porque alunos nessa fase da escolarização estão justamente na idade da maturação fisiológica e das descobertas sexuais: em outras palavras, há nesses jovens um interesse potencial em descobrir a sexualidade que se impõe fisiológica, social e psicologicamente em suas vidas.

\footnotetext{
'Professor Doutor Universidade Federal de São Carlos. Correio eletrônico: hyliolafer@gmail.com

2Secretaria de Educação do Estado de São Paulo, Brasil.

3 Licencianda Universidade Federal de São Carlos
} 
Revista Tecné, Episteme y Didaxis: TED. Año 2014, Número Extraordinario. ISSN Impreso: 0121-3814, ISSN web: 2323-0126

Memorias, Sexto Congreso Internacional sobre Formación de Profesores de Ciencias. 08 al 10 de octubre de 2014, Bogotá

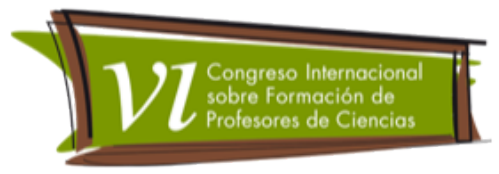

Sua inserção oficial como tema transversal (idem, 1997), ou seja, não vinculado ao conteúdo curricular de nenhuma disciplina específica mas que deve permear diversas áreas, permite que seja abordada com enfoques distintos e por diferentes professores, segundo formações específicas e afinidades. Em suma, aspectos biológicos, psicológicos e socioculturais relacionados à sexualidade podem ser entendidos como privilegiados para 0 trabalho escolar com adolescentes.

Nos estudos preliminares de aproximação da realidade escolar com a escola parceira deste trabalho verificou-se que apenas a disciplina Ciencias previa a sexualidade no planejamento, com inserção tímida de conteúdos referentes apenas ao ciclo menstrual e Doenças Sexualmente Transmissiveis (DST); por outro lado, entre os alunos constataram-se diversos casos de gravidez (indesejada) entre adolescentes, sugerindo que nesse aspecto $o$ ensino não atingia seus objetivos.

Esse panorama sugere, com relação a sexualidade, um ensino descontextualizado, ligado a uma determinada cultura escolar moderna, fragmentada e especializada, cujos "modos autoritários de interação social impedem a possibilidade de novas questões e não estimulam o desenvolvimento da curiosidade" (Louro, 2000, pág.34), que não parte de demandas dos estudantes. Possivelmente perpassa essa prática também o tabu referente a sexo na cultura brasileira: "a sexualidade se depara submersa em um espectro de valores morais, demarcados e demarcadores de condutas, usos e hábitos sociais" (Silva Jr., 2011, pág.218) que torna difícil sua abordagem.

Como complicador nesse contexto já problemático emerge a questão da submissão feminina: vivemos implícita ou explicitamente questões de gênero e sexualidade na cultura, sob influencia de enfoques distintos, e muitas vezes antagonicos, da mídia, igreja, família, círculo de amigos, movimentos sociais, e também da própria escola, palco da presente proposta. A componente biológica da sexualidade, que envolve os processos fisiológicos e os fenômenos organicos, é aquela que prevalece nas aulas de ciencias, por estar historicamente referendado a essa área do conhecimento; as perspectivas psicológica e cultural, indissociavelmente imbricadas à biológica, como as diferenças de genero, frequentemente são omitidas do discurso escolar, como consequência (e causa) de construções sociais (Heilborn, 1999) que enquadram essa temática como tabu. Assim, embora a sexualidade pudesse ser um tema de 
Revista Tecné, Episteme y Didaxis: TED. Año 2014, Número Extraordinario. ISSN Impreso: 0121-3814, ISSN web: 2323-0126

Memorias, Sexto Congreso Internacional sobre Formación de Profesores de Ciencias. 08 al 10 de octubre de 2014, Bogotá

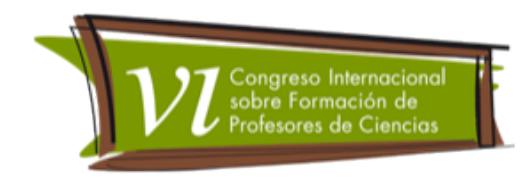

grande repercussão na educação escolar, é quase sempre recusado no universo prático do educador (Aquino 1997), devido a sua natureza polêmica.

Nesse contexto coloca-se a proposta que norteia este trabalho: investigar processos de formação docente desenvolvidos em grupos de encontro (ROGERS, 2002), pautados no diálogo e não-diretividade, tendo como desafio o ensino da sexualidade na escola, considerando aspectos das esferas biológicas, psicológicas e socioculturais dos/as jovens estudantes. Tomamos como marco teórico nessa formação a perspectiva humanista, que considera a liberdade para aprender e a não-diretividade (Rogers, 1978; 2002) como fundamentais ao processo formativo cujo objetivo seja a autonomia do aprendente; considerando também nesse processo o valor dos saberes docentes da experiencia (Tardif, 2000) e os processos de reflexão para e na ação (Schom, 1983).

\section{Grupo de Encontros Sexualidade na Escola}

A partir do quadro exposto, foi criado um grupo de encontro que visava discutir -e praticar- modos de abordar significativamente a sexualidade na escola. As propostas previstas curricularmente na escola giravam em torno de especificações técnicas sobre ciclo menstrual, gravidez, métodos contraceptivos e DST, com suas formas de profilaxia e tratamento. Uma abordagem bastante comoda para as licenciandas, uma vez que são conteúdos do campo das ciencias biológicas.

Certamente informações sobre a saúde e biologia reprodutiva são muito importantes, porém aparentemente a abordagem técnica utilizada nessa escola não se mostrava atraente para os jovens adolescentes, em processo de descobrimento de seus corpos e vivencia dos desejos sexuais: para eles estava premente a curiosidade sobre o sexo e o prazer a ele associado. Uma evidencia disso estava no fato de que, apesar desse currículo, havia na escola jovens adolescentes grávidas. Esse foi o principal problema identificado para nosso trabalho formativo: como abordar a sexualidade de maneira significativa para os jovens?

Foi nos grupos de encontro que as necessidades mais próximas da realidade foram ganhando forma, e emergiram estratégias que permitiram partir de dúvidas legítimas dos/as estudantes para uma discussão contextualizada: com uma dinamica simples, que consistiu em depositar anonimamente perguntas acerca 
Revista Tecné, Episteme y Didaxis: TED. Año 2014, Número Extraordinario. ISSN Impreso: 0121-3814, ISSN web: 2323-0126

Memorias, Sexto Congreso Internacional sobre Formación de Profesores de Ciencias. 08 al 10 de octubre de 2014, Bogotá

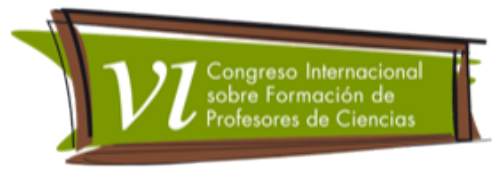

sexualidade numa urna, foi possível identificar as reais dúvidas e curiosidades dos adolescentes; essa abordagem introdutória foi adotada também em outras oportunidades, pois mostrou-se eficiente para adequar os encaminhamentos nas aulas.

Evidenciaram-se com esse processo, desenvolvido na sala de aula e discutidos no grupo, questões de genero, que inevitavelmente aparecem imbricadas com a sexualidade. Nesse contexto foi natural acontecer uma discussão mais ampla, que não se limitava a anatomia e fisiologia, mas que perpassava também relação com o corpo, respeito e prazer, considerando questões culturais de submissão feminina que permeiam as relações afetivas.

Ao longo dos anos as propostas nascidas na interface da escola com o grupo de encontro se diferenciaram segundo as turmas de adolescentes, que apresentaram dúvidas específicas, e também as influencias das participantes do grupo; espelhando as dinamicas dos grupos de encontro, todas as intervenções na escola também pautaram-se no diálogo franco e aberto, embora com enfoques diferentes: em algumas turmas foi investigada a diferença na maturação sexual de meninos e meninas; em outras foram desenvolvidos diferentes jogos na intenção de estimular trabalho em equipe e maior descontração; em outros momentos foram feitas dinamicas com separação de sexos para que pudessem acontecer diálogos sem constrangimento (a partir da constatação que as meninas não se sentiam a vontade para expor certas dúvidas diante dos meninos).

Importa ressaltar neste artigo os aspectos desse processo que marcaram a formação dessas docentes, que dizem respeito a liberdade para agir, a importância da reflexão sobre a prática, ao saber da experiencia, ao reposicionamento frente ao saber escolar introjetado ao longo da vida escolar e, como consequencia desses, a abertura para a análise dos fenômenos vivenciados na sala de aula que extrapolam os conteúdos biológicos.

Um elemento marcante refere-se à experiência: é somente na aplicação prática da proposta, vivenciada na sala de aula, que pode se concretizar (ou não) o que foi planejado. É nesse contexto que se desenvolvem os saberes da experiencia (TARDIF, 2000), que constituem, juntamente com saberes específicos e pedagógicos, o corpo de conhecimentos profissionais necessarios às praticas docentes. Tais saberes ganham sentido quando construídos e utilizados em 
Revista Tecné, Episteme y Didaxis: TED. Año 2014, Número Extraordinario. ISSN Impreso: 0121-3814, ISSN web: 2323-0126

Memorias, Sexto Congreso Internacional sobre Formación de Profesores de Ciencias. 08 al 10 de octubre de 2014, Bogotá

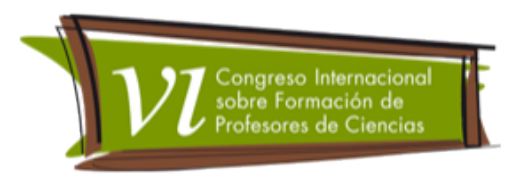

situações de trabalho particulares, situadas, que acontecem na vivencia docente em sala de aula: não podem ser simulados, dado o contexto variado, multifacetado, de certa forma imprevisível, inerente a cada turma de estudantes. Este aprendizado pode ser sintetizado nas palavras de uma licencianda: "para nós a principal pratica para a formação veio da experiência, e da possibilidade de refletir coletivamente sobre o que fomos vivendo ".

Um outro movimento ocorreu com o rompimento da abordagem biológicohigienista que as licenciandas traziam: a partir da realidade vivida na escola, das discussões no grupo de encontro e das pesquisas bibliograficas subsequentes, foi superada a proposta habitualmente praticada, que sanitariza e deforma a sexualidade, impedindo uma discussão franca -e significativa- com os estudantes. Com esse movimento as licenciandas sairam da zona de conforto dos conhecimentos estritamente biológicos, das concepções de educação e culturais a eles atreladas, e enveredaram para outras abordagens com sentido naquele contexto, experimentando um contato mais próximo -e intenso- com a realidade dos alunos.

Uma fala que sintetiza a formação aqui proposta foi trazida por uma das licenciandas: "Ter a liberdade para discutir no grupo tudo que acontecia na escola e ouvir as opiniões de todos mas sabendo que a decisão do que fazer seria minha, foi importante para ganhar confiança em meu trabalho". Nesse trecho fica evidente a importância da liberdade de agir para "ganhar confiança", ou em outras palavras, ganhar autonomia.

As dinamicas dos grupos de encontro, pautadas na horizontalidade das relações, assim como o espaço aberto pela escola parceira para proposição de ações, proporcionaram um ambiente de liberdade que permitiu às licenciandas serem protagonistas de suas práticas e realizar reflexões sobre seu próprio fazer docente a partir das realidades vivenciadas. Não houve, durante as reuniões do grupo, nenhuma imposição nos direcionamentos, mas apenas compartilhamento de ideias e opiniões: a liberdade de agir, aliada a possibilidade de dialogar livre e coletivamente, permitiu às próprias licenciandas identificar suas questões e buscar sua superação, refletindo sobre seus próprios planejamentos, ações, préconcepções e avaliações; isso fez com que se percebessem ativas e autoras no seu próprio processo formativo, condição fundamental para a construção da autonomia. 
Revista Tecné, Episteme y Didaxis: TED. Año 2014, Número Extraordinario. ISSN Impreso: 0121-3814, ISSN web: 2323-0126

Memorias, Sexto Congreso Internacional sobre Formación de Profesores de Ciencias. 08 al 10 de octubre de 2014, Bogotá

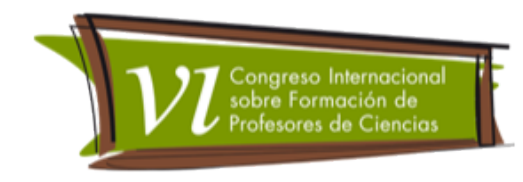

Um desafio na formação (inicial) dos professores, numa perspectiva de educação libertária e transformadora, está em conciliar a realidade encontrada nas escolas (multicultural, diversa, complexa), com as concepções de docencia que os licenciandos carregam de sua própria escolarização, na maioria dos casos impregnada por um modelo de ensino autoritário, fragmentado e transmissivo, e com pré-concepções da realidade modelados fortemente pela cultura. Constata-se, a partir do acompanhamento dessas licenciandas, que a formação docente não prescritiva aqui analisada proporciona autonomia para saber-se capaz de agir no universo complexo inerente a sala de aula, considerando no processo não apenas o contexto sociocultural e saberes prévios dos estudantes, mas também as próprias concepções de mundo.

\section{Referencias bibliográficas}

Aquino, J. G. (1997) Sexualidade Na Escola: Alternativas Teóricas E Práticas. $4^{a}$ Edição. São Paulo: Editora Summus

Brasil (1997). Parâmetros Curriculares Nacionais. Brasília: Mec/Sef.

Heilborn, M.L (Org) (1999). Sexualidade: O Olhar Das Ciências Sociais, Ims/Uerj. Rio De Janeiro: Editora Zahar.

Louro, G. L. (2000) O Corpo Educado: Pedagogias Da Sexualidade. 2a Edição. Belo Horizonte/Mg: Interlivros

Rogers, C. R. (1978) Liberdade Para Aprender. Belo Horizonte: Interlivros.

(2002) Grupos De Encontro. 8. Ed. São Paulo: Martins Fontes.

Schön, D. A. (1983) The Reflective Practitioner: How Professionals Think In Action London: Temple Smith.

Tardif, M. (2000) Saberes Profissionais Dos Professores E Conhecimentos Universitários. Revista Brasileira De Educação, 13, pág. 5-23.

Silva Junior, J. A. (2011) Sexualidade E Educação: Um Diálogo Necessario. Revista Lugares De Educação, 1(2), pág. 218-238. 